\title{
Using a Delphi process to determine optimal care for patients with pancreatic cancer.
}

Elizabeth A. Burmeister ${ }^{1,2}$, Susan J. Jordan ${ }^{1}$, Dianne L. O’Connell ${ }^{3,4,5,6}$, Vanessa L. Beesley ${ }^{1}$,

David Goldstein ${ }^{5,7}$, Helen M. Gooden ${ }^{6}$, Monika Janda ${ }^{8}$, Neil D. Merrett ${ }^{9,10}$, David Wyld ${ }^{11,12}$,

Rachel E. Neale ${ }^{1}$ for The Pancreatic Cancer Clinical Working Group.

${ }^{1}$ QIMR Berghofer Medical Research Institute, Brisbane, Australia

${ }^{2}$ School of Public Health, University of Queensland, Australia

${ }^{3}$ Cancer Council NSW, Sydney, Australia

${ }^{4}$ University of Newcastle, NSW, Australia

${ }^{5}$ University of New South Wales, Australia

${ }^{6}$ University of Sydney, NSW, Australia

${ }^{7}$ Prince of Wales Hospital, NSW, Australia

${ }^{8}$ Queensland University of Technology, Brisbane, Australia

${ }^{9}$ University of Western Sydney, NSW, Australia

${ }^{10}$ Bankstown Hospital, NSW, Australia

${ }^{11}$ Royal Brisbane and Women's Hospital, Brisbane, Australia

${ }^{12}$ School of Medicine, University of Queensland, Australia

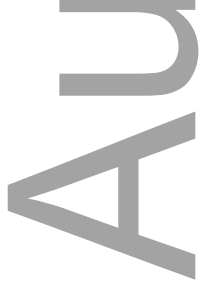

This is the author manuscript accepted for publication and has undergone full peer review but has not been through the copyediting, typesetting, pagination and proofreading process, which may lead to differences between this version and the Version of Record. Please cite this article as doi:

$\underline{10.1111 / \text { ajco.12450. }}$.

This article is protected by copyright. All rights reserved. 


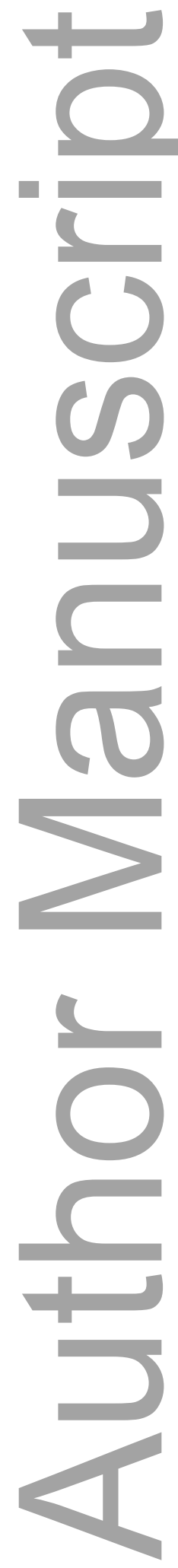

This article is protected by copyright. All rights reserved. 
Corresponding author: Elizabeth Burmeister

QIMR Berghofer Medical Research Institute

300 Herston Road

Herston

Queensland

Australia 4029

$\mathrm{Ph}:+61738453547$ Fax: + 61738453502

Email: Elizabeth.burmeister@qimrberghofer.edu.au

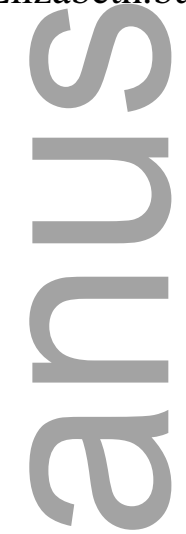

Word count: 3582

Number of references: 43

Number of figures / tables: $3=2$ figures +1 table and 1 supplementary content table

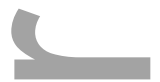

Short Title: Pancreatic Cancer Delphi

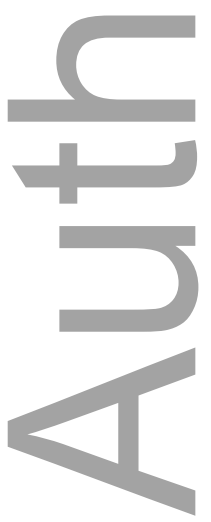




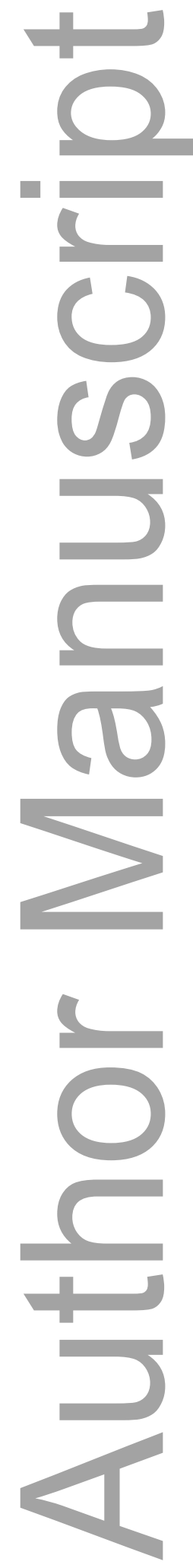

This article is protected by copyright. All rights reserved. 


\section{Pancreatic Cancer Clinical Working Group:}

Meera Agar, Flinders University \& Braeside Hospital; Luisa Algie, The Princess Alexandra Hospital; Fabio Brecciaroli, Caloundra Hospital; Ann Bullen, The Royal Brisbane and Women's Hospital; Matthew Burge, The Royal Brisbane and Women's Hospital; Bryan H. Burmeister, University of Queensland and Princess Alexandra Hospital; Susan Caird, Gold Coast University Hospital \& Griffith University; Donald Cameron, The Townsville Hospital; Philip Chan, University of Queensland \& The Royal Brisbane and Women's Hospital; Lorraine Chantrill, Campbelltown Hospital \& Garvan Institute; David Christie, Bond University \& Genesiscare; Yu Jo Chua, The Canberra Hospital; Peter H. Cosman, University of Western Sydney ; John Croese, The Prince Charles Hospital; Michelle Cronk, Nambour General Hospital; Mark Deuble, Princess Alexandra Hospital; Melissa Eastgate, The Royal Brisbane and Women's Hospital; David Fletcher, University of Western Australia; Jon Gani, John Hunter Hospital; David Goldstein, Prince of Wales Hospital; Peter Grimison, Chris O’Brien Lifehouse; Saurabh Gupta, The Wesley Hospital \& Princess Alexandra Hospital; George Hruby, University of Sydney \& Chris O’Brien Lifehouse; Michael Jefford, Peter MacCallum Cancer Centre; Stephen V. Lynch, Mater Private Hospital \& Princess Alexandra Hospital; Neil Merrett, Bankstown Hospital \& University of Western Sydney; Jennifer Powell, The Royal Brisbane and Women's Hospital; David Pryor, Princess Alexandra Hospital; Spiro Raftopoulos, Sir Charles Gairdner Hospital; Jaswinder S. Samra, Royal North Shore Hospital \& Macquarie University Hospital; Kellee Slater, Greenslopes Hospital \& Princess Alexandra Hospital; Nigel Spry, Sir Charles Gairdner Hospital; Guy Van Hazel, University of Western Australia; Jane Whelan, Princess Alexandra Hospital; A. Peter Wysocki, Logan Hospital \& Griffith University.

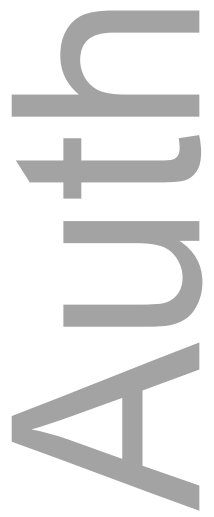




\section{Abstract}

Aim

Overall 5-year survival for pancreatic cancer is $\sim 5 \%$. Optimising the care that pancreatic cancer patients receive may be one way of improving outcomes. The objective of this study was to establish components of care which Australian health professionals believe important to optimally manage patients with pancreatic cancer.

\section{Methods}

Using a Delphi process, a multi-disciplinary panel of 250 health professionals were invited to provide a list of factors they considered important for optimal care of pancreatic cancer patients. They were then asked to score and then rescore (from one (no importance/disagree) to 10 (very important/agree) the factors. The mean and coefficient of variation scores were calculated and categorised into three levels of importance.

\section{Results}

Overall 63 (66\% of those sent the final questionnaire; $25 \%$ of those initially invited) health professionals from 9 disciplines completed the final scoring of 55 statements/factors encompassing themes of presentation/staging, surgery and biliary obstruction, multidisciplinary team details and oncology. Mean scores ranged from 3.7 to 9.7 with the highest related to communication and patient assessment. There was substantial intra- and interdisciplinary variation in views about MDT membership and roles.

\section{Conclusion}

Overall the opinions of Australian health professionals reflect international guideline recommended care; however they identified a number of additional factors focusing on where patients should be treated, the importance of clear communication and the need for multidisciplinary care which were not included in current clinical practice guidelines. Differences in priorities between specialty groups were also identified. 
Keywords: Delivery of Health Care, Delphi Technique, Health Services Needs and Demand, Pancreatic Neoplasms.

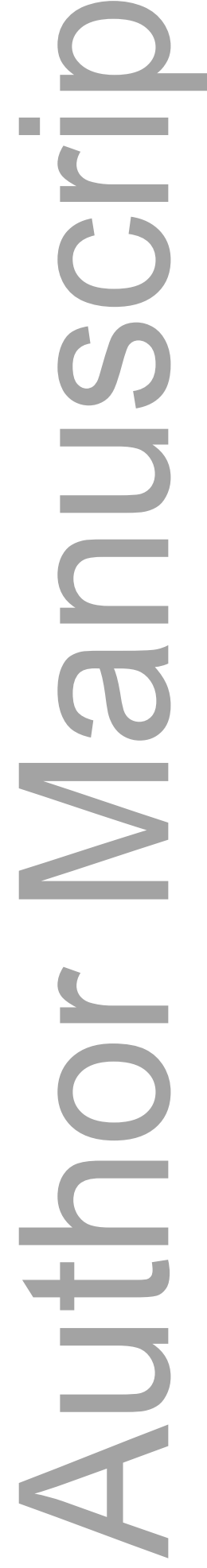




\section{Introduction:}

Pancreatic cancer is the 10th most commonly diagnosed cancer in more developed regions of the world. In Australia it is the 6th most common cancer diagnosis and the 4th leading cause of cancer related death. ${ }^{1}$ People diagnosed with pancreatic cancer have the poorest prognosis of any cancer. One-year survival is currently $15 \%$ and five-year all-stage survival for pancreatic cancer in Australia is $5.2 \%$, which mirrors other western countries. ${ }^{2,3}$ Current projections suggest that it will be the second leading cause of cancer death within 10 years as survival from other cancers improves. ${ }^{4,5}$

Provision of optimal care increases the likelihood of desired health outcomes. ${ }^{6,7}$ To facilitate this clinical practice guidelines/recommendations for pancreatic cancer have been published in Europe ${ }^{8-11}$ and the USA. ${ }^{12}$ However, the extent to which health professionals in the field agree with the guidelines, and if they consider all elements of the guidelines equally important is not known. In addition, guidelines may not cover some clinical situations or aspects of care that health professionals believe to be necessary for optimal management. ${ }^{13}$ Assessing the elements of care that specialist clinicians consider to be important for patients with pancreatic cancer and assessing whether these elements are evidence-based could assist in the modification of guidelines and/or identify areas where system changes or clinician education could help to improve patient outcomes.

One way of harnessing the opinions of a group of specialists is to use a Delphi process. This method has been used facilitate clinical consensus in a variety of medical situations. ${ }^{14-16}$ It begins with open-ended questions soliciting information from a panel of experts in the field. ${ }^{17}$ This is followed by ranking or scoring of the derived statements by the panel according to set criteria. The combined resultant scores/rankings are fed back to the panel members who are then invited to re-score the statements. The process is conducted anonymously, preventing domination of individuals and iterations of the scoring and feedback process repeated until consensus is reached or negligible change in scores is noted.

The aim of this study was to use a Delphi process to establish components of care which Australian health professionals believe are important to optimally manage patients diagnosed with pancreatic cancer. 


\section{Methods:}

\section{The Delphi process}

We used the literature, personal contacts and professional groups, including the Australian Pancreatic Cancer Genome Initiative ${ }^{18}$ and Cancer Council Australia, to identify health professionals involved in the care of pancreatic cancer patients from across Australia. We emailed these clinicians inviting them to participate and also asked them to nominate other clinicians who may be interested in participating. The panel consisted of surgeons, medical oncologists, radiation oncologists, gastroenterologists, palliative care specialists, nurses, allied health professionals, interventional radiologists and general practitioners. These experts were initially asked (online) to "...list all/any factors you consider important in the care of patients with suspected or confirmed pancreatic cancer." They were also asked about their specialty and years in practice.

The responses to the open-ended question were used to develop the quantitative questionnaire. Each response was grouped with those of similar themes and we eliminated duplicate statements. This process was done independently by two authors (EB and RN) and a structured list of statements was developed. Where possible, statements were used as written by participants. Some statements with similar inferences required merging to avoid duplication; these were discussed within the study team to avoid corrupting their original meanings.

Via email, we invited panel members to complete the quantitative questionnaire. They were asked to rate the importance of, or their level of agreement with, each statement on a scale of one (no importance/disagree) to 10 (very important/agree). Panel members could record "no opinion' for statements they felt were beyond their scope of expertise. We provided the mean and median scores for each statement from the initial questionnaire to those who had responded to either the open-ended question or the first quantitative questionnaire and asked them to re-score the statements in light of this information.

\section{Analyses}

The mean and coefficient of variation (CV) were calculated for each statement using the scores for all participants and also stratified according to specialty. The CV is the ratio of the standard deviation (SD) to the mean and gives the relative magnitude of the SD; it was multiplied by 10 for ease of reporting. 
Using a priori criteria each statement was categorized based on the mean score and $\mathrm{CV}$ as follows:

Mean 9-10; CV $<4$ : very important

Mean 6-8.9; CV < 4: moderately important

Mean 1-5.9; $\mathrm{CV}<4$ : unimportant

Any mean; $C V \geq 4$ : unable to agree.

We used analyses of variance (ANOVA) to assess differences between the specialty groups.

$\underline{\text { Ethics }}$

The Human Research Ethics Committees of the QIMR Berghofer Medical Research Institute and the University of Queensland approved this study. Completion of questionnaires was considered to imply consent.

\section{Results}

In June 2013, 250 health professionals involved in the care of pancreatic cancer patients were invited by email to complete the initial open-ended question (Figure 1). Of these, 78 (31\%) replied and suggested a total of 380 overlapping items that they considered important in the care of pancreatic cancer patients. These were reduced to 55 items that encompassed the following themes: presentation and staging; surgery and biliary obstruction; the management team (including multi-disciplinary team (MDT) details); oncology; and other (such as enrolling patients in clinical trials and establishing a national pancreatic cancer prospective database). The list of 55 items was then sent to the original 250 health professionals, irrespective of whether or not they responded to the first open-ended question. Following scoring of the initial items, the statements were resent to the 96 health professionals who had responded during round 1 or round 2. Of these, 63 (66\% of those sent the final questionnaire; $25 \%$ of those initially invited) rescored the items.

Specialties of the participants invited included surgery $(\mathrm{n}=56 ; 22 \%)$, medical oncology $(\mathrm{n}=$ $43 ; 17 \%)$, allied health and nursing $(n=40 ; 16 \%)$, gastroenterology $(n=29 ; 12 \%)$, palliative care $(n=28 ; 11 \%)$, radiation oncology $(n=13 ; 5 \%)$, and others $(n=41 ; 16 \%)$ which included interventional radiology, general practice, gerontology and medicine (Figure 2). The response proportion to the final questionnaire ranged from $10 \%$ (other) to $54 \%$ (radiation oncology). The specialties of the final questionnaire respondents were: $22 \%$ - medical 
oncology, $18 \%$ - surgery, $19 \%$ - palliative care, $18 \%$ - allied health and nursing, $11 \%$ radiation oncology and $6 \%$ from each of gastroenterology and others. Seventy-six respondents to the initial open-ended questionnaire (97\%) described their clinical experience. Of these $12,(16 \%)$ reported more than 20 years treating patients with pancreatic cancer and treating more than ten patients each year. The majority of respondents treated more than 10 patients each year $(n=43,57 \%)$ and years of experience were reported as less than 10 years, 10 to 20 years and more than 20 years by 30 (39\%), 25 (33\%) and 21 (28\%) clinicians respectively.

Based on the initial scores, 8 of the 55 statements (15\%) were classified as very important and $33(60 \%)$ as moderately important. The CV was greater than 4 for 14 (25\%) statements, including 8 that were considered unimportant. No items where the CV was less than 4 were classified as unimportant. Only two statements "All patients should have a full physical examination, geriatric assessment if elderly, assessment of comorbidities and performance status prior to any treatment" and "Patients should be fully aware of the risks and benefit of interventions prior to any treatment" were given a moderately-high or higher score by all participants.

The mean scores for almost half the statements $(n=24 ; 44 \%)$ increased between surveys but were unchanged for 17 statements $(31 \%)$, and decreased for $14(25 \%)$ statements. The majority $(\mathrm{n}=30 ; 55 \%)$ of CVs remained the same between surveys; $11 \%(\mathrm{n}=6)$ increased and $35 \%(\mathrm{n}=19)$ decreased between surveys.

Statements scored as very important or where consensus was not reached are displayed in Table 1 and are described further below within thematic categories (see Table, Supplementary Content 1 , which shows the final scores for all 55 statements, overall and stratified by specialty).

Presentation and Staging: Almost 25\% of the statements derived from the initial open-ended question related to presentation and staging $(\mathrm{n}=13 ; 24 \%)$. The need to conduct a full physical assessment prior to treatment and to develop standard staging guidelines were both rated as very important. The panel did not reach consensus about the value of positron electron tomography (PET) scans, endoscopic ultrasounds (EUS) or carbohydrate antigen 19.9 (CA19.9) as staging tools, with evidence of variability in the rated importance of these statements both between and within specialty groups. Palliative care specialists rated the 
value of PET scans more highly than surgeons (mean scores 8.4 and 5.1 respectively, $\mathrm{p}=$ 0.03 ) and had a lower CV (2 versus 4).

Surgery and biliary obstruction: The 9 statements related to surgery and biliary obstruction had the fewest responses with some high proportions $(9-91 \%)$ of the allied health, nursing and "other" groups indicating no opinion due to lack of expertise in the area. Amongst those who did respond, the statements "all patients with a small lesion and technically resectable disease plus adequate performance status should be offered a resection" and "Resectability should be assessed and surgery performed by surgeons who perform more than 5 pancreatic surgeries per year", were classified as very important. Consensus was not reached for 5 statements. Allied health /nursing and palliative care specialists rated the statement "Potential for coeliac plexus block should be discussed before any surgical procedure" much higher than the surgical specialists (scores 9.0, 7.2 and 3.3 respectively, $\mathrm{p}=0.02$ ).

Referrals and Multi-disciplinary team (MDT): Over a third of the survey statements $(n=19$; $35 \%$ ) referred to when and where treatment should occur, and which specialists should be involved. The statements "all patients with potentially resectable disease should be referred to a hepato-biliary surgeon" and "tumour resectability should be assessed by a MDT at a tertiary hospital" were thought very important with overall mean scores of 9.3 and 9.0 respectively.

No overall or within-specialty consensus was reached for the statement "On diagnosis all patients should be referred to palliative care" $(\mathrm{CV}=6)$. There was a significant difference in the scores between palliative care and surgical specialists with mean scores of 6.1 and 2.7 respectively, $(\mathrm{p}=0.03)$. Similarly, the panel did not agree on which patients should be presented at MDT meetings, with high inter- and intra-specialty variability.

Although surgeons and gastroenterologists had significant variation within their specialty groups $(\mathrm{p}<0.001)$ they thought it less important that "MDT meetings should include palliative care specialists" and that "symptom management should be discussed at an MDT" than allied health, nursing and palliative care specialists $(\mathrm{p}=0.02)$.

Oncology and Others: All the 14 oncology and "other" statements were classified as moderately or very important with participants able to reach consensus and ranking none as unimportant.

The statements that "patients should be fully aware of risks and benefits of interventions prior to any treatment" and "patients should be advised of the limitations of chemotherapy" were 
the highest scoring statements with total mean scores of 9.7 and 9.5 respectively and little variability across specialty.

Radiation oneologists regarded access to conformal radiotherapy as more important than other health professionals. Surgeons scored the statement "all patients should have a collaborative generalist/specialist care model" lower than all other health professional groups. This difference between surgical and allied health/nursing specialists was statistically $\operatorname{significant}(\mathrm{p}=0.03)$.

Gastroenterology, palliative care and allied health and nursing specialists rated the statement "careful attention to pain control is important, using nerve blocks if required" more highly than surgeons $(p=0.03)$.

\section{Discussion}

We used a Delphi process to identify factors that health professionals from a range of disciplines consider important in the care of patients with pancreatic cancer. As expected, many of the items rated as important are consistent with existing evidence-based clinical guidelines, but there were also items rated as important by health professionals that are not considered by guidelines. Furthermore, for some consensus-based or expert opinion-based items included in guidelines agreement on the importance of these between the health professionals we surveyed was not reached. We also found that the rating of particular issues varied substantially by clinical discipline.

Clinical guidelines have been developed by peak bodies in Europe and the USA, most notably the National Comprehensive Cancer Network $(\mathrm{NCCN})^{12}$ and the European Society for Medical Oncology (ESMO), ${ }^{9,} 11$ which describe clinical pathways from diagnosis to treatment for patients with pancreatic cancer. In Australia no national clinical practice guidelines have been developed that are specific to the care of patients with pancreatic cancer.

Comparing current guidelines with the opinions of clinicians working in the field identified some areas requiring further clarification, in particular the diagnosis and staging of pancreatic cancer. Respondents in this study rated highly the need for development of standard guidelines for staging. This was underscored by the very high variability in responses about the value of PET, CA19.9 and EUS. Lack of clarity about PET is also apparent in the guidelines, with NCCN stating that it is unclear if PET is useful and ESMO guidelines 
recommending PET not be used. Both organisations recommend that CA19.9 should only be used in treatment monitoring and that EUS be used as an adjunct to a pancreatic protocol computerised tomography (CT) or magnetic resonance imaging (MRI) only in those without biopsy-proven metastases. The high variation in scores for EUS amongst our participants may result from the inclusion of the words "all patients" in the statement as those with confirmed metastases would not benefit from the procedure.

It is notable that of the 55 items derived from panel members' responses, approximately half related in some way to access to treatment, where treatment should occur or who should be involved in different treatment aspects. This may be a recognition that pancreatic cancer patients require highly specialised care and the provision of treatment at specialist centres might improve outcomes. This could also reflect the substantial geographical dispersion of the Australian population and the finding of a trend towards poorer survival in rural and remote areas. ${ }^{19}$ The study participants agreed that patients should be managed as close to home as possible, but that standard guidelines should be developed to determine who would benefit from transfer to a tertiary centre. Improved access through video-link to tertiary centres was also considered important. Telehealth aims to remove barriers to accessing medical services for residents of rural and remote Australia, ${ }^{20}$ and there are International and Australian recommendations around its use. ${ }^{21}$ The Queensland state Department of Health estimates that use of Telehealth would reduce health costs by $30 \%{ }^{22}$ and is currently underused throughout Queensland. ${ }^{23}$

Access to specialist surgical management was particularly highlighted. There was high agreement that all patients with potentially resectable disease should be assessed by a hepatobiliary surgeon, ideally as part of a multidisciplinary team. The need for multidisciplinary assessment of resectability is specifically stated in guidelines ${ }^{12}$ and has been shown to improve surgical mortality rates $^{24}$ but it is unclear to what extent this currently occurs. Respondents also agreed that pancreatic cancer resections should occur in highvolume centres, reflecting guideline recommendations although definitions of high-volume vary across guidelines. The cut-off recommended by our panellists was consistent with the NCCN guidelines (15 surgeries/year). However, the National Cancer Institute (NCI) guidelines classify hospitals carrying out > 5 resections/year as high-volume and the British Society of Gastroenterology (BSG) guidelines ${ }^{25}$ do not give a value, but rather recommend that surgery be carried out in 'specialist centres'. The evidence available suggests different 
values (range 5 - 19) for high-volume classification. ${ }^{26,27}$ Few data support a role for surgeon volume independent of hospital volume, ${ }^{27,28}$ probably because these are highly correlated, but our participants nevertheless felt pancreatic resections should be undertaken by surgeons performing more than 5 per year. These data clearly show that clinicians feel that centralisation of surgical care for pancreatic cancer is important. In the USA, hospital volume for pancreatectomies more than tripled between 2000 and 2008 with the median volume increasing from 5 to $16^{26}$ whereas in Australia volume is increasing but resections are still performed in low-volume hospitals. ${ }^{29,30}$

Multidisciplinary care has become the accepted standard for cancer patients and has been shown to improve treatment access and timeliness. ${ }^{731}$ However, systematic review evidence suggests there is substantial variability in the way MDT meetings are incorporated into patient care $^{32}$ and this is reflected in our data, which show that clinicians value multidisciplinary care but vary in their views about the function of MDTs in the management of patients with pancreatic cancer. For example, in contrast to other specialties, surgeons were less likely to agree that all patients should be presented to MDTs and more likely to indicate that only potentially resectable patients should be presented to MDTs. The NCCN guideline also suggests that only patients without metastatic disease be presented at MDT meetings. However, The European Partnership for Action Against Cancer (EPAAC) recommend in their MDT policy document ${ }^{33}$ that MDTs co-ordinate cancer care at all stages. While there was strong consensus among our panellists across all specialties that palliative care specialists should be present at MDT meetings, the presence of allied health professionals was not consistently rated as important by surgeons. This may reflect the fact that surgeons lead most MDT meetings and may prioritise surgical and medical issues over psychosocial concerns. ${ }^{34}$ EPAAC guidelines emphasise the need for MDTs to address the supportive care and psychosocial needs of their patients. They also emphasise the need for coordination across different disciplines to achieve continuity of care. While our Delphi process identified the importance of care coordination, the reality is that in Australia there is considerable variability in the way that the coordination role is implemented. ${ }^{35}$ Adopting system-wide policies regarding MDTs and care coordination may be one way of improving the management of patients with pancreatic cancer.

The two top-scoring items in our study related to patient communication. Both items emphasised the importance of ensuring that patients are aware of the risks, benefits and 
limitations of treatment. While this should be standard in all clinical situations, it is particularly important for patients with pancreatic cancer where surgery can result in significant morbidity and, even with successful resection, median survival is poor at $\sim 20$ months. ${ }^{36}$ In addition, current chemotherapy regimens have limited survival benefit and a USA national cohort study showed that about three quarters $(69-81 \%)$ of patients with advanced cancer did not understand that the chemotherapy they were receiving was unlikely to result in cure. ${ }^{37}$

Up to $75 \%$ of patients with advanced pancreatic cancer report pain and it is one of the major factors adversely affecting quality of life. ${ }^{38-40}$ The need to manage pain was one of the highest-scoring items on the survey, but there was a lack of consensus about whether coeliac plexus neurolysis (CPN) should be discussed before embarking on any surgical procedure. CPN can prevent pain development for up to 6 months post-operatively ${ }^{41}$ and, while some studies suggest that CPN may not offer greater pain relief over opioid analgesia, it has fewer side effects. ${ }^{40}$ The NCCN guidelines do suggest that $\mathrm{CPN}$ should be considered at the time of palliative surgery.

A major strength of this study was the robust method we used to elicit opinions from experts in pancreatic cancer management. ${ }^{42,43}$ Key features of the Delphi process we used included: (1) the multi-disciplinary panel drawn from a wide range of medical and allied health fields; (2) each health professional rated the quality-of-care statements anonymously, limiting the potential for a single individual to dominate the proceedings; (3) we provided structured feedback, where following the first round of ratings the panel received the ratings from the entire group; (4) it was iterative, with two rating rounds allowing panel members to change their minds after deliberation; ${ }^{16}$ (5) it was internet-based and therefore less costly than other methods such as focus groups.

The study has two key limitations. Firstly, although a broad range of specialist clinicians participated, response rates were highly variable and some specialties (notably gastroenterology) were under-represented. For ethical reasons we were unable to capture detailed information about the non-responders so it is difficult to determine the representativeness of the final sample in terms of factors such as location of practice and years of experience. Secondly, some statements did not fully portray the clinical variability that underlies decisions about care. This particularly applies to those statements which commenced with the words "All patients". While the statements had been transcribed 
verbatim following responses to the open-ended questionnaire and to amend them would have resulted in a deviation from the Delphi method, some items may have scored more consistently had they been worded differently.

This work shows that, for the most part, clinicians' opinions reflect clinical guidelinerecommended care, albeit with some exceptions. However, clinicians identified a number of additional factors that are not incorporated in pancreatic-cancer specific guidelines, with a particular focus on where patients should be treated, the importance of clear communication and the need for multidisciplinary care. The lack of agreement about which patients and clinicians should be included in MDT meetings reinforces the notion that further in-depth investigations are required to identify the optimal composition and schedule of MDT meetings to improve and standardise practice in this area. Similarly, clinicians support the need to develop policies about transfer to tertiary centres and implementation of Telehealth to ensure that all patients with pancreatic cancer receive optimal multidisciplinary coordinated care.

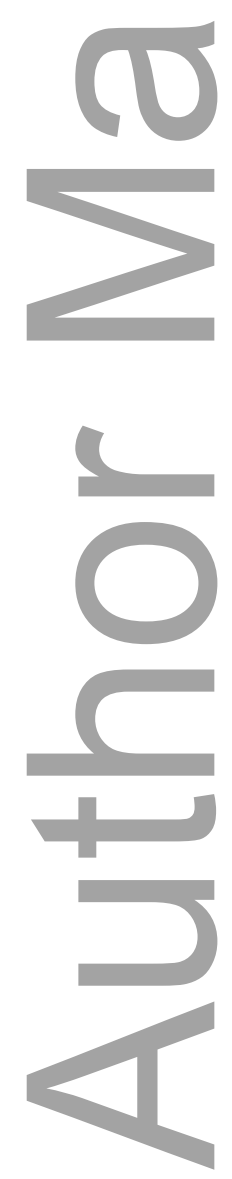




\section{Acknowledgments}

This study was funded by a National Health and Medical Research Council (NHMRC) (Australia) project grant (\# 613654) and has been conducted with full ethical approval. R Neale and S Jordan are funded by NHMRC fellowships and E Burmeister by a NHMRC scholarship. We would like to acknowledge the contribution of the pancreatic cancer clinical working group and the health professionals who participated in the Delphi process.

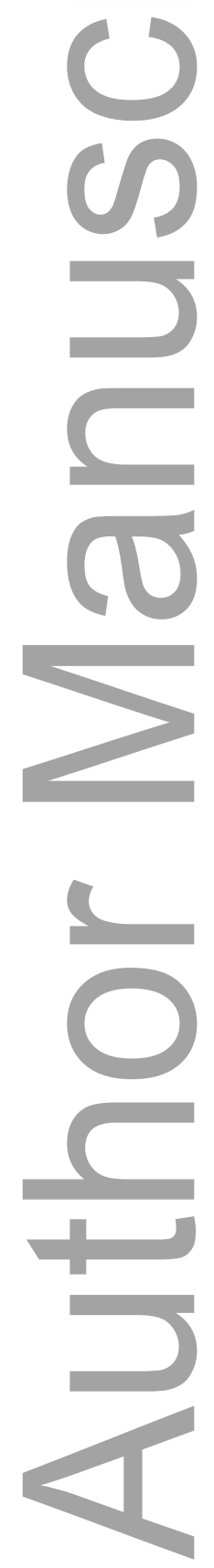




\section{References}

1. Australian Bureau of Statistics, 3303.0 - Causes of Death, Australia. 2012: Canberra.

2. Australian Institute of Health and Welfare, Cancer survival and prevalence in Australia: period estimates from 1982 to 2010. 2012, AIHW: Canberra.

3. Siegel, R., et al., Cancer statistics, 2014. CA Cancer J Clin, 2014. 64(1): p. 9-29.

4. Rahib, L., et al., Projecting cancer incidence and deaths to 2030: the unexpected burden of thyroid, liver, and pancreas cancers in the United States. Cancer Res, 2014. 74(11): p. 2913-21.

5. Cancer Institute NSW, Cancer incidence and mortality: projections 2011 to 2021. Sydney: May 2011.

6. Grimshaw, J.M. and I.T. Russell, Effect of clinical guidelines on medical practice: a systematic review of rigorous evaluations. Lancet, 1993. 342(8883): p. 1317-22.

7. Buanes, T.A., Pancreatic cancer-improved care achievable. World J Gastroenterol, 2014. 20(30): p. 10405-10418.

8. $\quad$ Verslype, C., et al., The management of metastatic pancreatic cancer:expert discussion and recommendations from the 14th ESMO/World Congress on Gastrointestinal Cancer, Barcelona, 2012. Annals of Oncology, 2013. 24(suppl 4): p. iv5 - iv10.

9. Cascinu, S., et al., Pancreatic cancer: ESMO Clinical Practice Guidelines for diagnosis, treatment and follow-up. Ann Oncol, 2010. 21 Suppl 5: p. v55-8.

10. Verslype, C., et al., The management of pancreatic cancer. Current expert opinion and recommendations derived from the 8th World Congress on Gastrointestinal Cancer, Barcelona, 2006. Ann Oncol, 2007. 18 Suppl 7: p. vii1-vii10.

11. Seufferlein, T., et al., Pancreatic adenocarcinoma: ESMO-ESDO Clinical Practice Guidelines for diagnosis, treatment and follow-up. Ann Oncol, 2012. 23 Suppl 7: p. vii33-40.

12. NCCN. NCCN Practice Guidelines for Pancreatic Cancer. Version 2.2014. 2014 [cited 2014 September 4]; (obtained on request from NCCN)].

13. Nuckols, T.K., et al., Rigorous development does not ensure that guidelines are acceptable to a panel of knowledgeable providers. J Gen Intern Med, 2008. 23(1): p. 37-44.

14. Bennett, C., et al., Consensus statements for management of Barrett's dysplasia and early-stage esophageal adenocarcinoma, based on a Delphi process.

Gastroenterology, 2012. 143(2): p. 336-46.

15. Iqbal, S.P.-Y., L, The Delphi method. The Psychologist, 2009. 22(7): p. 598 - 601.

16. Strosberg, J.R., et al., Systemic treatment in unresectable metastatic welldifferentiated carcinoid tumors: consensus results from a modified delphi process. Pancreas, 2013. 42(3): p. 397-404.

17. Hsu, C.C. and B.A. Sandford, The Delphi Technique: Making Sense Of Consensus. Practical Assessment, Research \& Evaluation, 2007. 12(10).

18. APCGI. Australian Pancreatic Cancer Genome Initiative; 2015 [cited 2015; Available from: http://www.pancreaticcancer.net.au/.

19. Cramb, S., K. Mengerson, and P. Baade, Atlas of Cancer in Queensland: geographical variation in incidence and survival, 1998 to 2007. 2011, Viertel Centre for Research in Cancer Control, Cancer Council Queensland.

20. Medicare. Telehealth. 201424 April, 2014 [cited 201410 November ]; Available from: http://www.medicareaustralia.gov.au/provider/incentives/telehealth/. 
21. Medicine, A.C.o.R.a.R. ACRRM Telehealth Guidelines. 2012 July 2012 [cited 2014 10 November]; Available from:

http://www.ehealth.acrrm.org.au/system/files/private/ATHAC\%20Telehealth\%20Stan dards\%20Framework\%202014-10.pdf.

22. Ross, N. Telehealth: The healthcare and aged care revolution that can pay for the whole NBN. ABC Technology and Games 201320 September, 2013 [cited 201410 Nov ]; Available from:

http://www.abc.net.au/technology/articles/2013/09/19/3852140.htm.

23. Armfield, N.R., P.A. Scuffham, and A.C. Smith, Inquiry into telehealth services in Queensland, in Queensland Parliament- Health and Community Services Committee. 2014.

24. Samra, J.S., et al., One hundred and seventy-eight consecutive pancreatoduodenectomies without mortality: role of the multidisciplinary approach. Hepatobiliary Pancreat Dis Int, 2011. 10(4): p. 415-21.

25. Pancreatric Section British Society of Gastroenterology, et al., Guidelines for the management of patients with pancreatic cancer periampullary and ampullary carcinomas. Gut, 2005. 54 Suppl 5: p. v1-16.

26. Finks, J.F., N.H. Osborne, and J.D. Birkmeyer, Trends in hospital volume and operative mortality for high-risk surgery. N Engl J Med, 2011. 364(22): p. 2128-37.

27. La Torre, M., et al., Hospital volume, margin status, and long-term survival after pancreaticoduodenectomy for pancreatic adenocarcinoma. Am Surg, 2012. 78(2): p. 225-9.

28. Pecorelli, N., et al., Effect of surgeon volume on outcome following pancreaticoduodenectomy in a high-volume hospital. J Gastrointest Surg, 2012. 16(3): p. 518-23.

29. Wylie, N., et al., Surgical management in patients with pancreatic cancer: a Queensland perspective. ANZ J Surg, 2012.

30. Lye, E.C., D. Gillies, and J. Gani, Pancreatico-Duodenectomy with high quality results in a medium volume centre. What are the Australian definitions of low volume? J Intergr Oncol, 2012. 1(2).

31. Gardner, T.B., et al., Effect of initiating a multidisciplinary care clinic on access and time to treatment in patients with pancreatic adenocarcinoma. J Oncol Pract, 2010. 6(6): p. 288-92.

32. Prades, J., et al., Is it worth reorganising cancer services on the basis of multidisciplinary teams (MDTs)? A systematic review of the objectives and organisation of MDTs and their impact on patient outcomes. Health Policy, 2014.

33. European Partnership Action Against Cancer consensus, g., et al., Policy statement on multidisciplinary cancer care. Eur J Cancer, 2014. 50(3): p. 475-80.

34. Devitt, B., J. Philip, and S.A. McLachlan, Team dynamics, decision making, and attitudes toward multidisciplinary cancer meetings: health professionals' perspectives. J Oncol Pract, 2010. 6(6): p. e17-20.

35. Freijser, L., et al., Cancer care coordination: building a platform for the development of care coordinator roles and ongoing evaluation. Aust J Prim Health, 2013.

36. Witkowski, E.R., J.K. Smith, and J.F. Tseng, Outcomes following resection of pancreatic cancer. J Surg Oncol, 2013. 107(1): p. 97-103.

37. Weeks, J.C., et al., Patients' expectations about effects of chemotherapy for advanced cancer. N Engl J Med, 2012. 367(17): p. 1616-25. 
38. Vickers, M.M., et al., Comorbidity, age and overall survival in patients with advanced pancreatic cancer - results from NCIC CTG PA.3: a phase III trial of gemcitabine plus erlotinib or placebo. Eur J Cancer, 2012. 48(10): p. 1434-42.

39. Carmichael, J., et al., Phase II study of gemcitabine in patients with advanced pancreatic cancer. Br J Cancer, 1996. 73(1): p. 101-5.

40. Arcidiacono, P.G., et al., Celiac plexus block for pancreatic cancer pain in adults. Cochrane Database Syst Rev, 2011(3): p. CD007519.

41. Lillemoe, K.D., et al., Current status of surgical palliation of periampullary carcinoma. Surg Gynecol Obstet, 1993. 176(1): p. 1-10.

42. Rowe, G. and G. Wright, The Delphi technique : Past,present, and future prospects Technological Forecasting \& Social Change, 2011. 78: p. 1487 - 1490.

43. Hussler, C., P. Muller, and P. Ronde, Is diversity in Delphi panelist groups useful? Evidence from a French forecasting exercise on the future of nuclear energy. Technological Forecasting and Social Change, 2011. 78(9): p. 1642 - 1653.

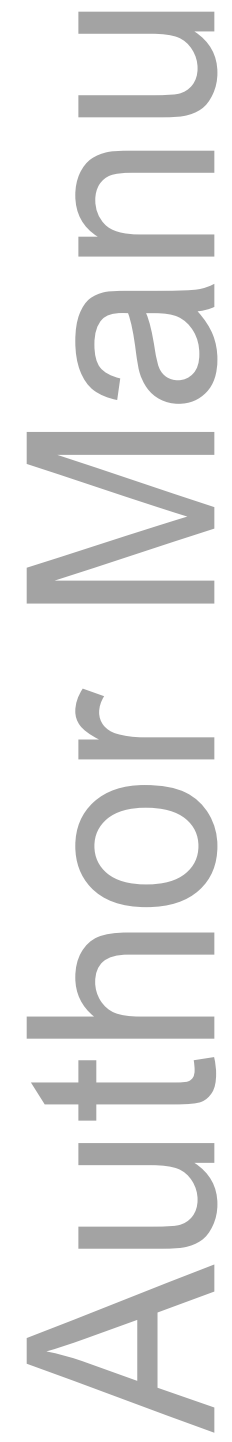


Figure Legends

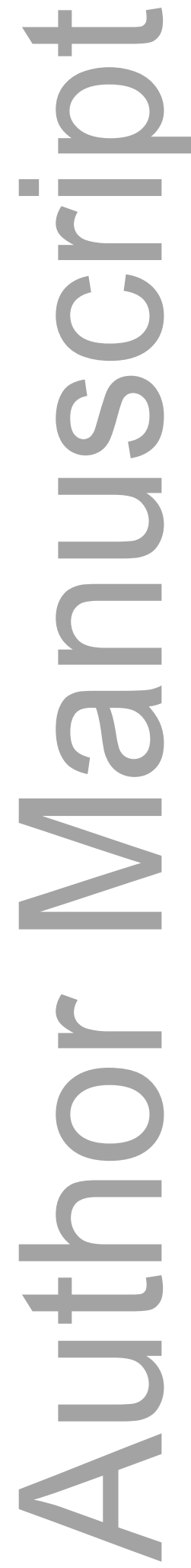


Table 1: Statements with highest importance or for which consensus was not reached, mean scores and coefficients of variation by health professional group.

\begin{tabular}{|c|c|c|c|c|c|c|c|c|c|}
\hline & & $\begin{array}{l}\text { Surg } \\
\text { ery }\end{array}$ & $\begin{array}{l}\text { Gastr } \\
\text { o- } \\
\text { enter } \\
\text { ology }\end{array}$ & $\begin{array}{l}\text { Medi } \\
\text { cal } \\
\text { Oncol } \\
\text { ogy }\end{array}$ & $\begin{array}{l}\text { i Radia } \\
\text { tion } \\
\text { Oncol } \\
\text { ogy }\end{array}$ & $\begin{array}{l}\text { Allied } \\
\text { Health } \\
\& \\
\text { Nursing }\end{array}$ & $\begin{array}{l}\text { Palli } \\
\text { ative } \\
\text { Care }\end{array}$ & $\begin{array}{l}\text { Oth } \\
\text { ers }\end{array}$ & $\begin{array}{c}\text { Tot } \\
5 \text { al }\end{array}$ \\
\hline & $\mathrm{bs}^{+}$ & & Mear & n score & e (coeffic & cient of $\mathbf{v}$ & variatic & on) & \\
\hline \multicolumn{10}{|l|}{ Presentation and Staging ( $n=13$ statements) } \\
\hline \multicolumn{10}{|l|}{ Very important: } \\
\hline $\begin{array}{l}\text { All patients should have a full physical examination, } \\
\text { geriatric assessment if elderly, assessment of } \\
\text { comorbidities and performance status prior to any } \\
\text { treatment }\end{array}$ & 59 & $\begin{array}{l}8.9 \\
(2)\end{array}$ & $\begin{array}{l}10.0 \\
(0)\end{array}$ & $\begin{array}{l}9.2 \\
(1)\end{array}$ & $9.1(1)$ & $\begin{array}{l}9.0 \\
(2)\end{array}$ & $\begin{array}{l}9.3 \\
(2)\end{array}$ & $\begin{array}{r}8.8 \\
(2)\end{array}$ & $\begin{array}{r}9.2 \\
(2)\end{array}$ \\
\hline $\begin{array}{l}\text { Standard guidelines for staging should be } \\
\text { developed }\end{array}$ & 60 & $\begin{array}{l}8.5 \\
(3)\end{array}$ & $\begin{array}{c}10.0 \\
(0)\end{array}$ & $\begin{array}{l}9.4 \\
(1)\end{array}$ & $9.1(1)$ & $\begin{array}{l}9.3 \\
(1)\end{array}$ & $\begin{array}{l}8.6 \\
(2)\end{array}$ & $\begin{array}{l}8.8 \\
(2)\end{array}$ & $\begin{array}{l}9.1 \\
(2)\end{array}$ \\
\hline \multicolumn{10}{|l|}{ Unable to reach consensus: } \\
\hline $\begin{array}{l}\text { If disease appears to be localised a PET scan } \\
\text { should be performed }\end{array}$ & 56 & $\begin{array}{l}5.1 \\
(4)\end{array}$ & $\begin{array}{l}8.4 \\
(3)\end{array}$ & $\begin{array}{l}6.1 \\
(5)\end{array}$ & $7.7(2)$ & $\begin{array}{l}7.4 \\
(3)\end{array}$ & $\begin{array}{l}8.4 \\
(2)\end{array}$ & $\begin{array}{l}6.8 \\
(3)\end{array}$ & $\begin{array}{r}6.9 \\
(4)\end{array}$ \\
\hline All patients should have an EUS & 56 & $\begin{array}{l}6.2 \\
(5)\end{array}$ & $\begin{array}{l}6.6 \\
(6)\end{array}$ & $\begin{array}{l}6.4 \\
(3)\end{array}$ & $5.4(4)$ & $\begin{array}{l}7.2 \\
(3)\end{array}$ & $\begin{array}{l}5.5 \\
(4)\end{array}$ & $\begin{array}{l}5.0 \\
(6)\end{array}$ & $\begin{array}{r}6.1 \\
(4)\end{array}$ \\
\hline $\begin{array}{l}\text { All patients presenting with ongoing epigastric or } \\
\text { back pain should have a CA19.9 blood test }\end{array}$ & 56 & $\begin{array}{l}5.9 \\
(6)\end{array}$ & $\begin{array}{l}4.0 \\
(8)\end{array}$ & $\begin{array}{l}4.6 \\
(7)\end{array}$ & $4.3(6)$ & $\begin{array}{l}5.3 \\
(2)\end{array}$ & $\begin{array}{l}5.3 \\
(4)\end{array}$ & $\begin{array}{l}4.5 \\
(1)\end{array}$ & $\begin{array}{r}4.9 \\
(6)\end{array}$ \\
\hline \multicolumn{10}{|l|}{$\begin{array}{l}\text { Surgery and Biliary Obstruction (BO) ( } n=9 \\
\text { statements ) }\end{array}$} \\
\hline \multicolumn{10}{|l|}{ Very Important: } \\
\hline $\begin{array}{l}\text { All patients with a small lesion and technically } \\
\text { resectable disease plus adequate performance } \\
\text { status should be offered a resection }\end{array}$ & 57 & $\begin{array}{l}9.2 \\
(1)\end{array}$ & $\begin{array}{c}10.0 \\
(0)\end{array}$ & $\begin{array}{l}9.1 \\
(1)\end{array}$ & $9.3(1)$ & $\begin{array}{c}10.0 \\
(0)\end{array}$ & $\begin{array}{l}8.8 \\
(1)\end{array}$ & $\begin{array}{l}8.7 \\
(2)\end{array}$ & $\begin{array}{r}9.2 \\
(1)\end{array}$ \\
\hline $\begin{array}{l}\text { Resectability should be assessed and surgery } \\
\text { performed by surgeons who perform more than } 5 \\
\text { pancreatic surgeries per year }\end{array}$ & 53 & $\begin{array}{l}8.7 \\
(2)\end{array}$ & $\begin{array}{l}10.0 \\
(0)\end{array}$ & $\begin{array}{l}8.7 \\
(2)\end{array}$ & $9.3(1)$ & $\begin{array}{l}9.2 \\
(2)\end{array}$ & $\begin{array}{l}8.8 \\
(1)\end{array}$ & $\begin{array}{l}8.5 \\
(2)\end{array}$ & $\begin{array}{l}9.0 \\
(2)\end{array}$ \\
\hline \multicolumn{10}{|l|}{ Unable to reach consensus: } \\
\hline $\begin{array}{l}\text { Potential for coeliac plexus block should be } \\
\text { discussed before any surgical procedure }\end{array}$ & 41 & $\begin{array}{l}3.3 \\
(6)\end{array}$ & $\begin{array}{l}6.6 \\
(5)\end{array}$ & $\begin{array}{l}5.9 \\
(4)\end{array}$ & $5.5(6)$ & $9.0(-)$ & $\begin{array}{l}7.2 \\
(2)\end{array}$ & $\begin{array}{r}7.0 \\
(-)\end{array}$ & $\begin{array}{r}5.8 \\
(5)\end{array}$ \\
\hline $\begin{array}{l}\text { Potentially resectable patients should not have a } \\
\text { tissue biopsy prior to surgery }\end{array}$ & 46 & $\begin{array}{l}5.3 \\
(5)\end{array}$ & $\begin{array}{l}3.6 \\
(11)\end{array}$ & $\begin{array}{l}4.5 \\
(5)\end{array}$ & $3.4(4)$ & $\begin{array}{l}4.5 \\
(2)\end{array}$ & $\begin{array}{l}5.3 \\
(4)\end{array}$ & $\begin{array}{l}6.0 \\
(5)\end{array}$ & $\begin{array}{r}4.7 \\
(5)\end{array}$ \\
\hline $\begin{array}{l}\text { Patients with resectable disease should not be } \\
\text { stented prior to surgery unless surgery is delayed }\end{array}$ & 42 & $\begin{array}{l}5.7 \\
(5)\end{array}$ & $\begin{array}{l}9.6 \\
(1)\end{array}$ & $\begin{array}{l}5.6 \\
(5)\end{array}$ & $7.5(2)$ & $\begin{array}{l}9.0 \\
(0)\end{array}$ & $\begin{array}{l}7.1 \\
(3)\end{array}$ & $\begin{array}{l}7.0 \\
(0)\end{array}$ & $\begin{array}{l}6.8 \\
(4)\end{array}$ \\
\hline $\begin{array}{l}\text { A SEMS should be used instead of a plastic stent if } \\
\text { biliary drainage is indicated prior to surgery }\end{array}$ & 36 & $\begin{array}{l}5.7 \\
(6)\end{array}$ & $\begin{array}{l}7.2 \\
(5)\end{array}$ & $\begin{array}{l}6.9 \\
(3)\end{array}$ & $6.5(2)$ & $9.0(-)$ & $\begin{array}{l}6.8 \\
(3)\end{array}$ & $\begin{array}{l}5.5 \\
(1)\end{array}$ & $\begin{array}{l}6.6 \\
(4)\end{array}$ \\
\hline $\begin{array}{l}\text { BO should be managed surgically if PS and } \\
\text { prognosis satisfactory in non-resectable patients }\end{array}$ & 48 & $\begin{array}{l}5.2 \\
(4)\end{array}$ & $\begin{array}{l}2.2 \\
(8)\end{array}$ & $\begin{array}{l}4.5 \\
(3)\end{array}$ & $4.8(3)$ & $\begin{array}{l}5.5 \\
(1)\end{array}$ & $\begin{array}{l}5.7 \\
(4)\end{array}$ & $\begin{array}{l}6.0 \\
(5)\end{array}$ & $\begin{array}{r}4.8 \\
(4)\end{array}$ \\
\hline \multicolumn{10}{|l|}{ MDT and Referrals ( $n=19$ statements ) } \\
\hline \multicolumn{10}{|l|}{ Very Important: } \\
\hline $\begin{array}{l}\text { All patients with potentially resectable disease } \\
\text { should be referred to an hepato-biliary surgeon }\end{array}$ & 59 & $\begin{array}{l}9.9 \\
(0)\end{array}$ & $\begin{array}{l}8.2 \\
(5)\end{array}$ & $\begin{array}{l}9.6 \\
(1)\end{array}$ & $9.7(1)$ & $\begin{array}{c}10.0 \\
(0)\end{array}$ & $\begin{array}{l}8.7 \\
(2)\end{array}$ & $\begin{array}{l}7.8 \\
(3)\end{array}$ & $\begin{array}{r}9.3 \\
(2)\end{array}$ \\
\hline $\begin{array}{l}\text { Tumour resectability should be assessed by a MDT } \\
\text { at a tertiary hospital }\end{array}$ & 60 & $\begin{array}{l}8.4 \\
(2)\end{array}$ & $\begin{array}{c}10.0 \\
(0)\end{array}$ & $\begin{array}{l}9.3 \\
(1)\end{array}$ & $9.1(1)$ & $\begin{array}{l}9.6 \\
(1)\end{array}$ & $\begin{array}{l}8.4 \\
(1)\end{array}$ & $\begin{array}{l}7.7 \\
(3)\end{array}$ & $\begin{array}{r}9.0 \\
(1)\end{array}$ \\
\hline
\end{tabular}

This is the author manuscript accepted for publication and has undergone full peer review but has not been through the copyediting, typesetting, pagination and proofreading process, which may lead to differences between this version and the Version of Record. Please cite this article as doi: 10.1111/ajco.12450.

This article is protected by copyright. All rights reserved. 
Unable to reach consensus:

Only patients who are potentially suitable for resection should be presented to a MDT

$61 \quad 5.1 \quad 1.2$

$\begin{array}{llllll}4.3 & 2.0(5) & 1.8 & 4.3 & 4.8 & 3.6\end{array}$

On diagnosis all patients should be referred to palliative care

$61 \begin{array}{cc}2.7 & 2.8 \\ & (10)\end{array}$

(6)

3.6

(5)

$3.1(5)$

(7)

(5)

(4) (7)

Oncology and Other ( $\mathrm{n}=14$ statements )

\section{Very Important:}

Patients should be fully aware of the risks and

benefit of interventions prior to any treatment

Patients should be advised of the limitations of

chemotherapy

$63 \begin{array}{cc}9.6 & 10.0 \\ (1) & (0)\end{array}$

61

$9.5 \quad 10.0$

9.7

(1) $9.0(2)$

$\begin{array}{lll}6.1 & 4.3 & 4.0\end{array}$

Careful attention to pain control is important, using

nerve blocks if required

$58 \begin{array}{cc}8.3 & 10.0 \\ (2) & (0)\end{array}$

9.5

$9.1(1)$

(6)

(5)

(7) (6)

$+=$ Obs = Total number of respondents with an opinion; PET = Positron emission tomography; EUS = Endoscopic

Ultrasound; SEMS = Self-expanding metal stent; MDT = Multi-disciplinary team

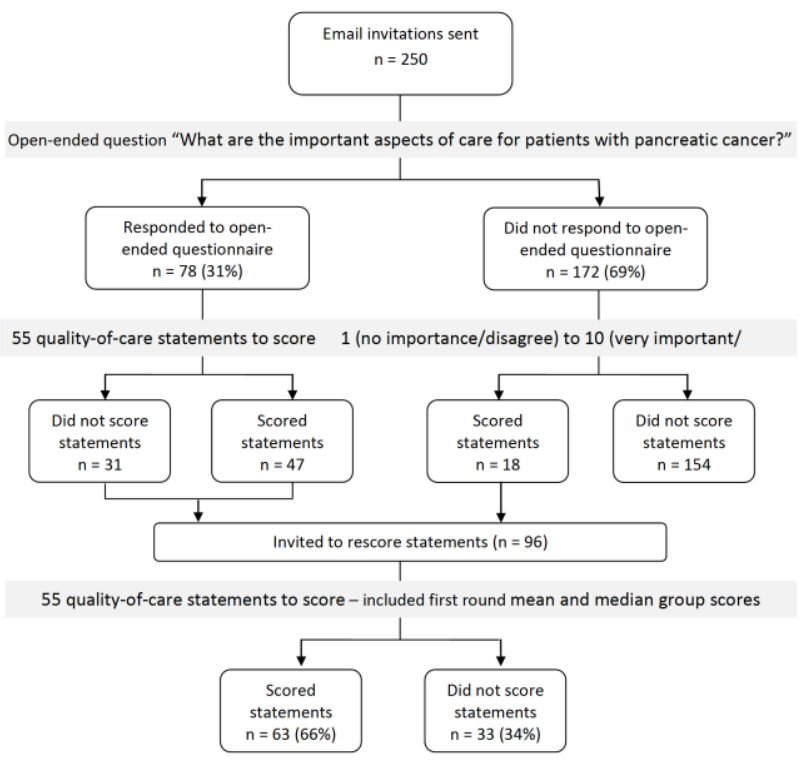

Figure 1: Consort diagram for the number of health professionals participating in the modified Delphi process.

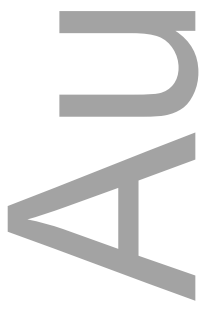

This article is protected by copyright. All rights reserved. 


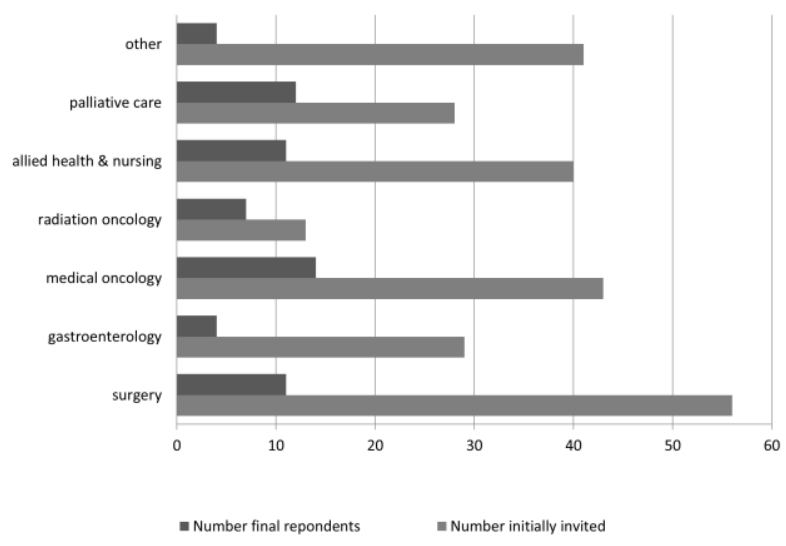

Figure 2: Numbers of invited and final responders by specialty

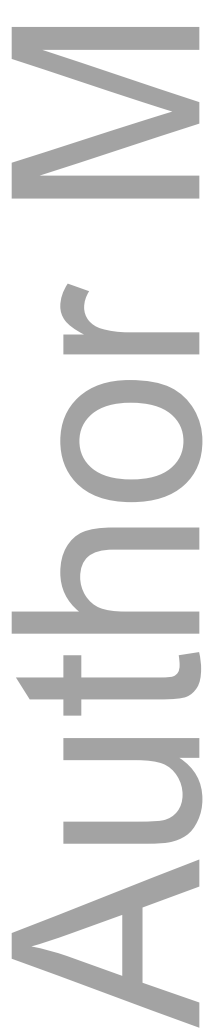




\section{University Library}

\section{- M I N E R VA}

\section{A gateway to Melbourne's research publications}

Minerva Access is the Institutional Repository of The University of Melbourne

\section{Author/s:}

Burmeister, EA;Jordan, SJ;O'Connell, DL;Beesley, VL;Goldstein, D;Gooden, HM;Janda, M;Merrett, ND;Wyld, D;Neale, RE

Title:

Using a Delphi process to determine optimal care for patients with pancreatic cancer

Date:

2016-06-01

\section{Citation:}

Burmeister, E. A., Jordan, S. J., O'Connell, D. L., Beesley, V. L., Goldstein, D., Gooden, H. M., Janda, M., Merrett, N. D., Wyld, D. \& Neale, R. E. (2016). Using a Delphi process to determine optimal care for patients with pancreatic cancer. ASIA-PACIFIC JOURNAL OF CLINICAL ONCOLOGY, 12 (2), pp.105-114. https://doi.org/10.1111/ajco.12450.

Persistent Link:

http://hdl.handle.net/11343/290853 